\title{
Kontribusi Kepemimpinan Transformasi dan Komitmen Organisasi terhadap Kinerja Karyawan UMKM
}

\author{
Tri Darma Rosmala Sari ${ }^{1}$ \\ Fakultas Ekonomi dan Bisnis \\ Universitas Teknokrat Indonesia, \\ Indonesia
}

\author{
Yusra Fernando 2 \\ Fakultas Teknik dan Ilmu Komputer \\ Universitas Teknokrat Indonesia, \\ Indonesia
}

Surel : tridarma_rosmalasari@teknokrat.ac.id

\begin{abstract}
ABSTRAK
Penelitian ini bertujuan untuk memberikan pedoman manajer dalam memperbaiki efektifitas gaya kepemimpinan transformasi dan komitmen organisasi. khususnya di UMKM. Penelitian dilakukan pada UMKM di Lampung. Data penelitian diperoleh melalui kuisioner yang disebarkan kepada karyawan UMKM yang memiliki produk unggulan agroindustri dan agrobisnis dan dianalisa menggunakan aplikasi Smart PLS. Hasil penelitian yaitu Kepemimpinan transformasi berpengaruh positif terhadap kinerja karyawan. Namun komitmen organisasi tidak memediasi hubungan antara kepemimpinan transformasi dan kinerja karyawan serta Kepemimpinan Transformasi tidak berpengaruh positif terhadap Komitmen Organisasi. Kontribusi penelitian ini dapat dijadikan sebagai pedoman manajer/ pemilik perusahaan dalam memperbaiki efektifitas gaya kepemimpinan transformasi dan komitmen organisasi, dalam unit usahanya.
\end{abstract}

Kata Kunci: Kepemimpinan Transformasi; Komitmen Organisasi; Kinerja Karyawan.

\section{Transformation Leadership Contribution and Organizational Commitment to the Performance of MSME Employees}

\begin{abstract}
This study aims to provide guidelines for managers in improving the effectiveness of transformational leadership styles and organizational commitment. especially in UMKM. The research was conducted at MSMEs in Lampung. The research data were obtained through questionnaires distributed to MSME employees who have superior agro-industry and agribusiness products and analyzed using the Smart PLS application. The result of this research is that transformation leadership has a positive effect on employee performance. However, organizational commitment does not mediate the relationship between transformational leadership and employee performance and Transformational leadership has no positive effect on Organizational Commitment. This research can be used as a guideline for company managers / owners in improving the effectiveness of transformational leadership styles and organizational commitment within their business units.
\end{abstract}

Keywords: Employee Performance; Leadership Transformation; Organizational Commitment.

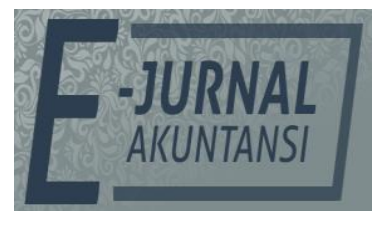

e-ISSN 2302-8556

Vol. 31 No. 1

Denpasar, Januari 2021

Hal. 106-115

DOI:

10.24843/EJA.2021.v31.i01.p08

PENGUTIPAN:

Sari, T.D.R., \& Fernando, Y. (2021). Kontribusi Kepemimpinan

Transformasi dan Komitmen Organisasi terhadap Kinerja Karyawan UMKM. E-Jurnal Akuntansi, 31(1), 106-115

RIWAYAT ARTIKEL: Artikel Masuk: 9 Agustus 2020 Artikel Diterima: 21 Januari 2021

Artikel dapat diakses : https://ojs.unud.ac.id/index.php/Akuntansi/index 


\section{PENDAHULUAN}

Indonesia termasuk kedalam Masyarakat Ekonomi Asean (MEA) yang dicerminkan dengan adanya perdangan bebas, dengan mudahnya produk produk dari Luar Negeri masuk ke Dalam Negeri. Sebagian pelaku usaha di Indonesia rata - rata bergerak dalam skala ekonomi mikro kecil dan menengah. Sebesar 96\% tenaga kerja diberdayakan pada UMKM (Usaha Mikro, Kecil dan Menengah) (www.detikfinance.com). Jumlah usaha kecil di Indonesia sebesar 93,4\%, usaha menengah 5,1\%, namun UMKM memiliki masalah pada akses pembiayaan, peluang usaha, kapasitas SDM dan kelembagaan UMKM. (www.Merdeka.com). Namun pertumbuhan UMKM di Provinsi lampung baru sebesar 9,17\% (www.cnbcindonesia.com).

Perusahaan harus mampu meningkatkan kinerja organisasi agar dapat memenangkan persaingan. Salah satu kunci faktor keberhasilan organisasi adalah melalui kinerja karyawan dan gaya kepemimpinan yang diterapkan dalam organisasi tersebut. Salah satu fungsi pemimpin yaitu mengendalikan sumber daya yang dimilikinya untuk mencapai tujuan organisasi. Kepemimpinan transformasi adalah suatu system yang dapat merubah dan mentransformasi seseorang (Hall, J., Johnson, S., Wysocki, A. \& Kepner, 2002). Komitmen organisasi juga merupakan salah satu variabel yang dapat berpengaruh siginifikan dalam meningkatkan kinerja karyawan. Ada pengaruh mediasi komitmen organisasi diantara kepemimpinan transformasi dan kinerja tugas karyawan (Almutairi, 2015). Penelitian ini bertujuan untuk memberikan pedoman manajer dalam memperbaiki efektifitas gaya kepemimpinan transformasi dan komitmen organisasi.

Penelitian terdahulu menjelaskan bahwa ada pengaruh signifikan antara kepemimpinan transformasi dan kinerja tugas karyawan (Al-Amin, 2017) dan (Ali et al., 2014). Kepemimpinan transformasi memiliki pegaruh dalam memotivasi karyawan secara efektif (Advani \& Abbas, 2015), (Bass et al., 2003) (Sundi, 2013) dan (Paracha et al., 2018). Eliyana et al., (2019) dalam penelitiannya menggunakan sample manajer level menengah di Pelabuhan Indonesia III menyatakan bahwa kepemimpinan transformasi memiliki hubungan langsung terhadap komitmen organisasi, namun kepemimpinan transformasi tidak berpengaruh signifikan terhadap kinerja tugas. Penelitian (Siswatiningsih et al., 2019) dengan objek karyawan RS Umum Ahmad Dahlan menyatakan bahwa komitmen organisasional dan kepemimpinan transformasi berpengaruh positif dan signifikan terhadap kinerja karyawan. Alshehhi et al., (2019) menguji kepemimpinan transformasi, komitmen organisasi di Perusahaan Publik di Arab, hasilnya menunjukkan bahwa kepemimpinan transformasi berhubungan positif terhadap komitmen afermatif dan kinerja karyawan. Daniel \& Purwanti, (2015) menjelaskan bahwa bahwa komitmen karyawan terhadap organisasi yang tinggi akan meningkatkan kinerja karyawan. Masih terdapat ketidakkonsistenan hasil penelitian terdahulu dan sedikitnya penelitian yang menggunakan data UMKM menjadi pendorong peneliti untuk melakukan penelitian ini.

Pemimpin transformasional adalah pemimpin yang berfungsi sebagai peran model dan sangat dihormati dan dipercaya oleh bawahan, yang mampu menampung keluhandan kebutuhan karyawan (Yukl \& Becker, 2006). Empat komponen kepemimpinan menurut Bass \& Avolio, (1990) yaitu; 1.) Karismatik 
(dealized influence), merepresentasikan pemimpin yang bekerja keras untuk meningkatkan kepercayaannya dalam mempengaruhi sikap karyawan. 2.) Inspirasional (inspirational motivation) Merepresentasikan kemampuan pemimpin untuk bertindak sebagai role model dan menginspirasi subordinate untuk menekankan usaha mereka terhadap shared visions. 3.) Stimulasi intelektual (intellectual stimulation), yaitu kemampuan seorang pemimpin dalam mempengaruhi bawahannya untuk ikut menyelesaikan masalah organisasi. 4.) Perhatian secara individual (individualized consideration), yaitu kemampuan seorang pemimpin dalam memberikan perhatian terhadap bawahannya dengan cara memberikan bantuan untuk peningkatan keberhasilan bawahan. Pemimpin transformasional akan mampu menciptakan lingkungan yang dapat membuat bawahan merasa memiliki ikatan emosi yang kuat dengan pemimpin melalui keyakinan dan kepercayaan. (Deluga, 1990).

Menurut Mowday et al., (1979) menjelaskan bahwa definisi Komitmen organisasi sebagai identifikasi dan keterlibatan karyawan dalam organisasi. Karakteristik komitmen organisasi menurut Mowday et al., (1982) yaitu bantuan dan penerimaan yang kuat terhadap tujuan dan nilai-nilai organisasi, kesiapan untuk bekerja keras, serta keinginan kuat untuk tetap berada dalam organisasi. Klasifikasi komitment organisasional terdiri atas tiga dimensi, yaitu; 1). Komitmen afektif (affective commitment), merupakan komitmen yang melibatkan emosi bawahan terhadap organisasi. 2). Komitmen continuance (continuance commitment), merupakan komitmen yang didasarkan biaya yang sudah dikeluarkan karena bawahankeluar dari organisasi. 3). Komitmen normatif (normative commitment), merupakan komitmen yang melibatkan perasaan bawahan terhadap tugas - tugas yang diberikan oleh organisasi. (Allen \& Meyer, 1990). Perbedaan dari ketiga dimensi komitmen organisasi menurut (Allen \& Meyer, 1990) yaitu sebagai berikut.

"Employees with strong affective commitment remain because they want to, those with strong continuance commitment remain because they need to, and those with strong normative commitment because they feel they thought to do so". Kinerja karyawan merupakan tingkat keberhasilan karyawan dalam melaksanakan tugas dan tanggung jawabnya. Tsui et al., (1997) menjelaskan komponen yang digunakan untuk mengevaluasi kinerja karyawan yaitu kualitas, efisiensi, upaya, profesionalisme, dan kemampuan dalam melaksanakan pekerjaan utama, kemampuan untuk menggunakan akal sehat, pengetahuan dan kreativitas karyawan. Kinerja karyawan merupakan prestasi perbandingan antara hasil kerja dengan standar yang ditetapkan.

Menurut Cho et al., (2019) menguji hubungan kepemimpinan transformasi dan komitmen organisasi di Korea dan US dan hasilnya adalah kepemimpinan transformastional berhubungan positif terhadap komitmen afektif. Eliyana et al., (2019) dalam penelitiannya menggunakan sample manajer level menengah di Pelabuhan Indonesia III menyatakan bahwa kepemimpinan transformasi memiliki hubungan langsung terhadap komitmen organisasi Lee, (2005) menguji pengaruh kepemimpinan dan perubahan anggota pimpinan terhadap komitmen organisasi. Hasil penelitiannya menunjukkan bahwa transformational leadership berhubungan positif dengan komitmen organisasional. 
Gaya kepemimpinan transformasi berpengaruh positif terhadap komitment organisasi. (Clinebell et al., 2013).

$\mathrm{H}_{1}$ : Kepemimpinan Transformasi berpengaruh positif terhadap Komitmen Organisasi.

Menurut Febrina, (2020) menyatakan bahwa komitmen organisasi berpengaruh positif terhadap kinerja. Zefeiti \& Mohamad, (2017) dalam penelitiannya menyatakan bahwa komitmen organisasi memiliki hubungan signifikan terhadap kinerja tugas. Komitmen organisasi yang tinggi akan berpengaruh positif terhadap kinerja karyawan (Ramli, 2019).

$\mathrm{H}_{2}$ : Komitmen organisasi berpengaruh positif dan signifikan terhadap Kinerja karyawan.

Menurut Gao et al., (2020) menguji hubungan antara kepemimpinan transformasi dan kinerja dan hasilnya adalah bahwa kepemimpinan transformasi berhubungan positif dengan kinerja. Bass et al., (2003) menjelaskan bahwa kepemimpinan transformasional berpengaruh positif terhadap kinerja karyawan. Kepemimpinan transformasi berpengaruh positif terhadap kinerja karyawan. Anshori et al., (2020).

$\mathrm{H}_{3}$ : Kepemimpinan transformasi berpengaruh positif terhadap kinerja karyawan. Berdasarkan kajian teori, model penelitian ini yaitu sebagai berikut.

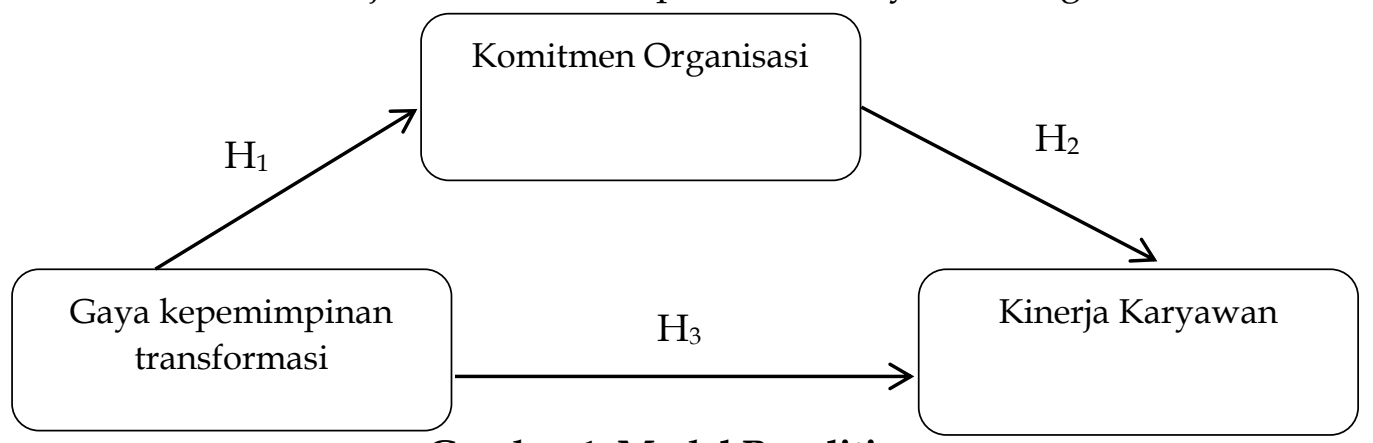

Gambar 1. Model Penelitian

Sumber: Eliyana\& Muzakki, 2019

\section{METODE PENELITIAN}

Populasi penelitian ini adalah UMKM di lampung. Data yang digunakan dalam penelitian ini adalah data primer yang diperoleh dengan menyebarkan kuisioner Metode pengumpulan data menggunakan purposive sampling dengan alasan bahwa karyawan yang menjadi responden sudah memiliki pengalaman bekerja lebih dari 2 tahun. Hasil pengumpulan data yang memenuhi kriteria karyawan telah bekerja selama 2 tahun dan responden berasal dari UMKM yang memiliki kriteria usaha unggul yaitu memiliki produk unggulan agroindustri dan agrobisnis seperti pengolahan keripik pisang, tenun tapis, penggilingan padi, usaha wisata alam, pantai, usaha kopi robusta, karet, kelapa, usaha sapi potong, Data penelitian diperoleh melalui kuisioner yang disebarkan kepada UMKM. Uji hipotesis dilakukan dengan menggunakan Smart PLS.

Pengukuran variabel kepemimpinan transformasi menggunakan instrument (Bass \& Avolio, 1994). Komitmen organisasi menggunakan instrumen yang dikembangkan oleh (Meyer \& Allen, 1984). Indikator Kinerja Karyawan menggunakan instrumen yang digunakan oleh (Tsui et al., 1997). Pertanyaan atau 
pernyataan dalam kuesioner untuk masing-masing variabel dalam penelitian ini diukur dengan menggunakan skalaLikert dan jawaban diberi skor, yaitu: nilai 1 = sangat tidak setuju, 2 = tidak setuju, $3=$ netral, $4=$ setuju, $5=$ sangat setuju .

Analisis dalam Smart PLS terdiri atas analisis outer model, dimana merupakan pengujian yang dilakukan untuk mengukur seberapa jauh indikator dapat menjelaskan variabel laten. Pengujian berikutnya dalam smart PLS yaitu inner model. Inner model merupakan pengujian hipotesis yang dilakukan untuk melihat pengaruh antara variabel laten dengan variabel laten lainnya.

Pengukuran Outer Model menggunakan tiga ukuran yaitu; 1). Convergent Validity, dinilai berdasarkan korelasi antara item score AVE yang dihitung dengan PLS. Convergent validity sangat baik apabila skor AVE (Average Variance Extracted) diatas 0,5 (Henseler et al., 2009). 2) Discriminant Validity; dinilai dengan dua metode yaitu metode Fornell-Larcker; membandingkan square roots atas AVE dengan korelasi vertical laten, dan metode Crossloading menyatakan bahwa semua item harus lebih besar dari konstruk lainnya (Al-Gahtani et al., 2007). 3). Cronbach Alpha, uji reliabilitas dilakukan dengan menggunakan metode Cronbach Alpha.Pengujian inner model dilakukan dengan melihat persentase varian yang dijelaskan yaitu $\mathrm{R}^{2}$ dan Uji t-statistik diperoleh melalui prosedur bootstraping.

\section{HASIL DAN PEMBAHASAN}

Pengujian Outer Model dilakukan untuk mengetahui apakah pengukuran yang digunakan layak dan valid. Uji reliabilitas dan validitas responden berjumlah 105 Data bias berjumlah 27 responden, sehingga data yang bisa dianalisis berjumlah 78 responden. Hasil pengujian dalam penelitian ini menunjukkan tidak ada permasalahan reliabilitas dan validitas.

Tabel 1. Reliabilitas dan Validitas

\begin{tabular}{lccc}
\hline Konstruk & Composite Reliability & Cronbach Alpha & AVE \\
\hline Kepemimpinan & 0,814 & 0,699 & 0,523 \\
Komitmen Organisasi & 1,000 & 1,000 & 0,503 \\
Kinerja Karyawan & 0,800 & 0,672 & 1,000 \\
\hline
\end{tabular}

Sumber: Data Penelitian, 2020

Path Coefficients digunakan untuk menjelaskan hubungan tiap konstruk dari masing - masing variabel dijelaskan oleh masing - masing indikator. Ahlemann, (2010) menjelaskan bahwa adanya signifikansi hubungan antar variabel jika path coefficients bernilai 0.050 .

Nilai $R^{2}$ untuk kinerja karyawan sebesar 0.250 , artinya bahwa kinerja karyawan sebagai variabel dependen dapat dijelaskan oleh kepemimpinan transformasi sebesar 25\%, sisanya sebesar $75 \%$ dijelaskan oleh variabel lain yang tidak diuji. 


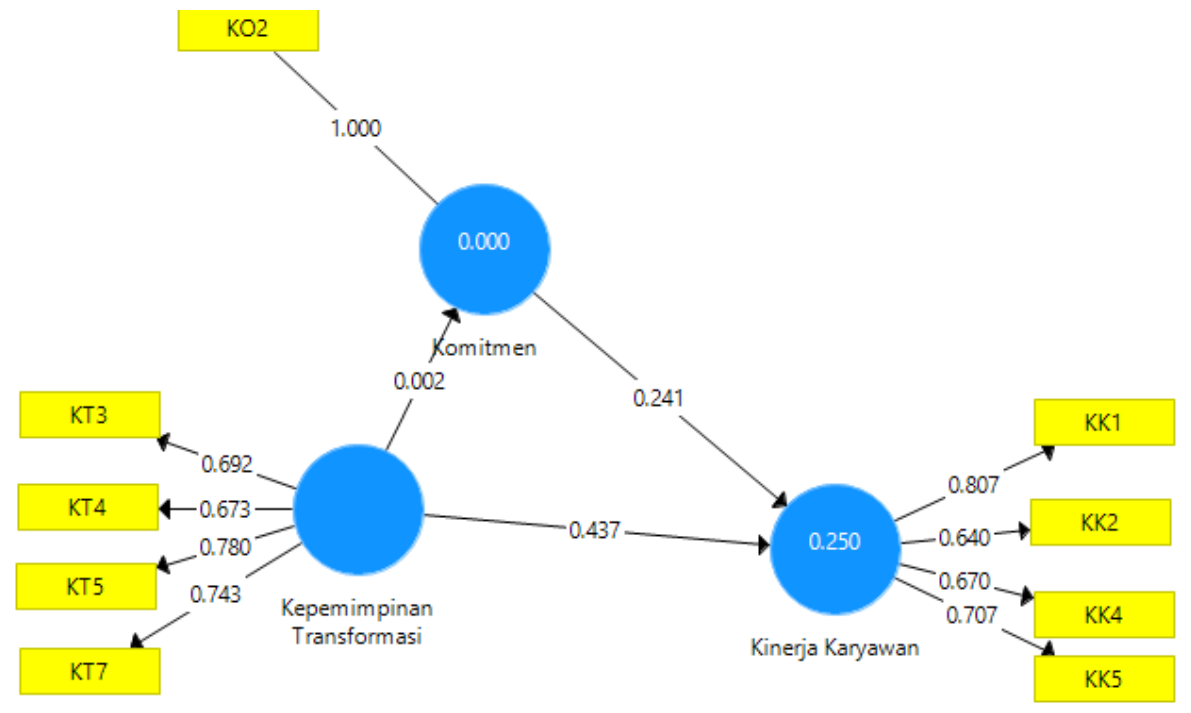

Gambar 1. Path Coefficients

Sumber: Data Penelitian, 2020

Berdasarkan Tabel 2, $\mathrm{H}_{1}$ tidak terdukung, artinya, secara statistik dapat ditunjukkan bahwa kepemimpinan transformasi tidak mempunyai pengaruh langsung terhadap komitmen organisasi. Hal ini menunjukkan bahwa komitmen karyawan pada organisasinya tidak semata mata dilandasi oleh adanya kepemimpinan transformasional. Pengaruh kepemimpinan transformasional terhadap komitmen karyawan akan lebih kuat jika ada kepuasan kerja Eliyana \& Muzakki, (2019) dan pemberdayaan psikologi Qing et al., (2018) serta kepemimpinan transformasional lebih cocok diterapkan di UMKM yang dinamis (Indartono, 2018). Berdasarkan Tabel 2, $\mathrm{H}_{2}$ tidak terdukung, artinya, secara statistik dapat ditunjukkan bahwa komitmen karyawan tidak mempunyai pengaruh langsung terhadap kinerja.

Tabel 2. Pengujian Hipotesis

\begin{tabular}{lcccc}
\hline Arah Jalur & $\begin{array}{c}\text { Koefisien } \\
\text { Jalur }\end{array}$ & T Statistik & T Tabel & Hipotesis \\
\hline $\begin{array}{l}\text { Kepemimpinan } \\
\text { Transformasi - }\end{array}$ & 0,460 & 4,252 & 1,96 & Hipotesis Terdukung \\
$\begin{array}{l}\text { Kinerja Karyawan } \\
\begin{array}{l}\text { Kepemimpinan } \\
\text { Transformasi - }\end{array}\end{array}$ & 0,003 & 0,018 & 1,96 & $\begin{array}{c}\text { Hipotesis Tidak } \\
\text { Terdukung }\end{array}$ \\
$\begin{array}{l}\text { Komitmen } \\
\text { Komitmen -> } \\
\text { Kinerja Karyawan }\end{array}$ & 0,243 & 1,881 & 1,96 & $\begin{array}{c}\text { Hipotesis Tidak } \\
\text { Terdukung }\end{array}$ \\
\hline
\end{tabular}

Sumber: Data Penelitian, 2020

Kondisi lingkungan kerja seperti gaji yang diberikan pelaku UMKM sering tidak sesuai dengan standar akan menurunkan motivasi dan komitmen karyawan untuk tetap berada didalam perusahaan. (Robbins and Coulter, 2010). Berdasarkan nilai t-hitung yang lebih besar dari t tabel yaitu 4,252 >1,96, berarti koefisien jalur signifikan, maka H3 yang menyatakan bahwa Kepemimpinan transformasi berpengaruh positif terhadap kinerja karyawan terdukung. Hal ini berarti gaya pemimpin yang memotivasi mampu meningkatkan kinerja karyawan. Hasil penelitian ini sejalan dengan hasil penelitian (Bass et al., 2003) 
yang menjelaskan bahwa kepemimpinan transformasional berpengaruh positif terhadap kinerja karyawan.

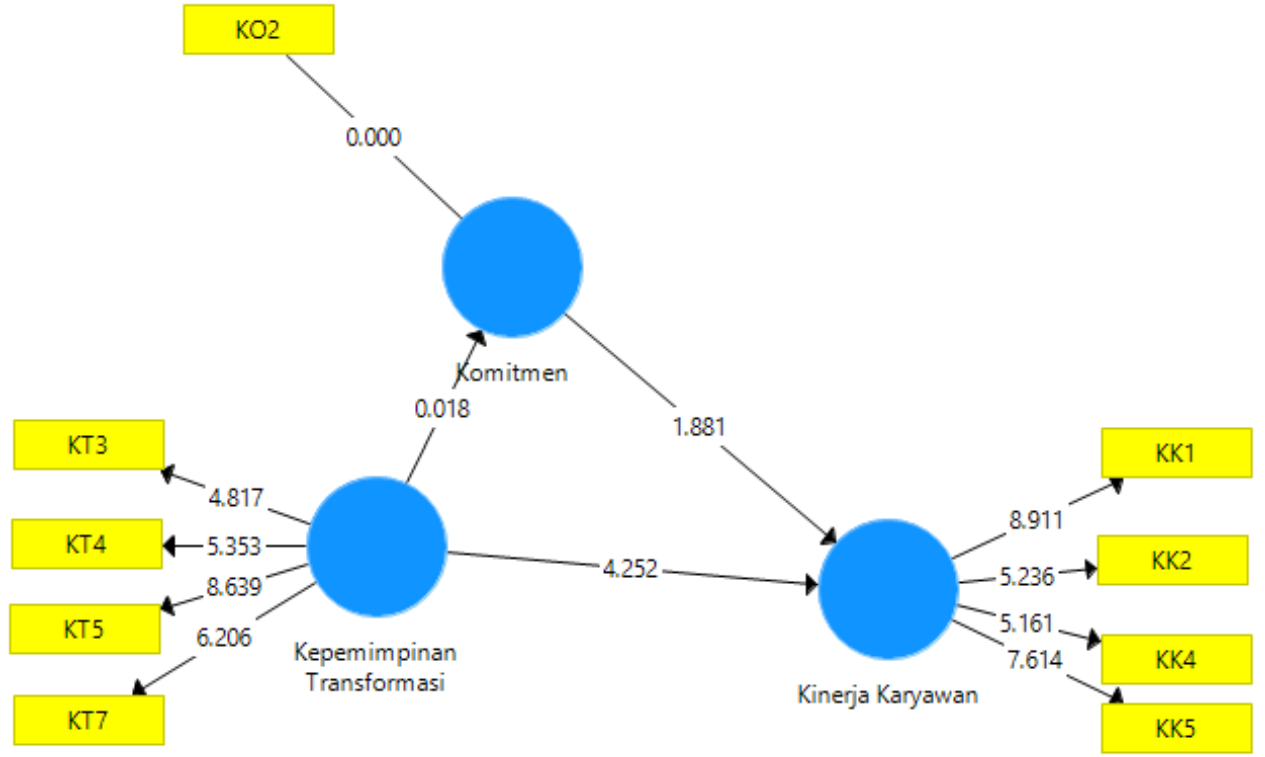

Gambar 2. Hasil Bootstraping

Sumber: Data Penelitian, 2020

\section{SIMPULAN}

Secara statistik dapat disimpulkan bahwa kepemimpinan transformasi tidak mempunyai pengaruh langsung terhadap komitmen organisasi. Hal ini menunjukkan bahwa komitmen karyawan pada organisasinya tidak semata mata dilandasi oleh adanya kepemimpinan transformasional. Berdasarkan Tabel 2, $\mathrm{H}_{2}$ tidak terdukung, artinya, secara statistik dapat ditunjukkan bahwa komitmen karyawan tidak mempunyai pengaruh langsung terhadap kinerja mereka. H3 yang menyatakan bahwa Kepemimpinan transformasi berpengaruh positif terhadap kinerja karyawan terdukung. Hal ini berarti gaya pemimpin yang memotivasi mampu meningkatkan kinerja karyawan. Hasil penelitian ini sejalan dengan hasil penelitian (Bass et al., 2003) yang menjelaskan bahwa kepemimpinan transformasional berpengaruh positif terhadap kinerja karyawan.

Penelitian ini memberikan informasi kepada Pemilik UMKM bahwa kepemimpinan transformasi dimana pemimpin mampu memotivasi dan bertindak sebagai role model, dapat meningkatkan kinerja karyawan. Penelitian selanjutnya dapat menggunakan model atau gaya kepemimpinan lainnya yang dikaitkan dengan kinerja karyawan. Sampel penelitian hanya diambil dari UMKM yang ada di kota Bandarlampung, sehingga hasil penelitian tidak dapat dijadikan sebagai dasar generalisasi. Untuk memperluas dan mengembangkan penelitian ini populasi dapat diperluas dengan menggunakan UMKM yang tersebar di Indonesia.

Penulis ingin mengucapkan terima kasih khusus kepada Kementerian Riset dan Teknologi / Badan Riset dan Inovasi Nasional (KEMENRISTEK/BRIN) Republik Indonesia. 


\section{REFERENSI}

Advani, A., \& Abbas, Z. (2015). Impact of Transformational and Transactional Leadership Styles on Employees 'Performance of Banking Sector in Pakistan " Crime Near Schools Impact of Organizational Justice Performance of Banking Sector (Issue November).

Al-Amin, M. (2017). Transformational leadership and employee performance mediating effect of employee engagement. North South Business Review, 7(2), 28-40.

Al-Gahtani, S. S., Hubona, G. S., \& Wang, J. (2007). Information technology (IT) in Saudi Arabia: Culture and the acceptance and use of IT. Information and Management, 44(8), 681-691. https:// doi.org/10.1016/j.im.2007.09.002

Ali, N., Ali, S., Ahsan, A., Rahman, W., \& Jan Kakakhel, S. (2014). Effects of leadership styles on job satisfaction, organizational citizenship behavior, commitment and turnover intention (empirical study of private sector schools' teachers). Life Science Journal, 11(SPEC. ISSUE 3), 175-183.

Allen, N. J., \& Meyer, J. P. (1990). The measurement and antecedents of affective, continuance and normative commitment to the organization. Journal of Occupational Psychology. https:// doi.org/10.1111/j.2044-8325.1990.tb00506.x

Almutairi, D. O. (2015). The Mediating Effects of Organizational Commitment on the Relationship between Transformational Leadership Style and Job Performance. International Journal of Business and Management, 11(1), 231. https://doi.org/10.5539/ijbm.v11n1p231

Alshehhi, S., Abuelhassan, A. E., \& Bhaumik, A. (2019). The Influence of Transformational Leadership on Employees "Performances Through Organizational Commitment Within Public Sectors in United Arab Emirates ( Uae ). International Journal of Innovative Technology and Exploring Engineering (IJITEE), 8(8), 527-540.

Anshori, M. Y., Karya, D. F., Muslihah, N., \& Herlambang, T. (2020). Analysis Of Transformational Leadership Style For Employee Performance With Job Satisfaction As Intervening Variable. 29(9), 3967-3973.

Ariyanto, D., Andayani, G. W., \& Putri, I. G. A. P. (2020). Influence of Justice, Culture and Love of Money Towards Ethical Perception on Tax Evasion with Gender as Moderating Variable. Journal of Money Laundering Control, 23(1), 245-266. https:// doi.org/10.1108/JMLC-06-2019-0047

Ariyanto, D., \& Dewi, A. A. (2019). Oportunistik Incumbent dalam Penganggaran Pendapatan dan Belanja pada Pemilihan Kepala Daerah Serentak Tahun 2017. Jurnal Ilmiah Akuntansi Dan Bisnis, 41-55. https://doi.org/10.24843/jiab.2019.v14.i01.p05

Bass, B. M., \& Avolio, B. J. (1990). Developing Transformational Leadership: 1992 and Beyond. Journal of European Industrial Training. https://doi.org/10.1108/03090599010135122

Bass, B. M., \& Avolio, B. J. (1994). Transformational leadership, organizational culture. International Journal of Public Administration, 17(3-4), 541-554. https://doi.org/10.1080/01900699408524907

Bass, B. M., Avolio, B. J., Jung, D. I., \& Berson, Y. (2003). Predicting unit performance by assessing transformational and transactional leadership. Journal of Applied Psychology. https:// doi.org/10.1037/0021-9010.88.2.207 
Cho, Y., Shin, M., Billing, T. K., \& Bhagat, R. S. (2019). Transformational leadership, transactional leadership, and affective organizational commitment: a closer look at their relationships in two distinct national contexts. Asian Business and Management, 18(3), 187-210. https://doi.org/10.1057/s41291-019-00059-1

Clinebell, S., Skudiene, V., Trijonyte, R., \& Reardon, J. (2013). Impact Of Leadership Styles On Employee Organizational Commitment. Journal of Service Science (JSS), 6(1), 139-152. https:/ / doi.org/10.19030/jss.v6i1.8244

Daniel, F., \& Purwanti, A. (2015). The Impact of Organizational Culture and Job Satisfaction to Organizational Commitment and Employees Job Performance (An Empirical Study at a University in Tangerang). September 2016, 1-18. https://doi.org/10.13140/RG.2.1.1196.4240

Deluga, R. J. (1990). The Effects of Transformational,Transactional, and Laissez Faire Leadership Characteristics on Subordinate Influencing Behavior. Basic and Applied Social Psychology. https://doi.org/10.1207/s15324834basp1102_6

Dewi, A. A., \& Ariyanto, D. (2019). "Koh Ngomong" and A Desire to Do Whistleblowing: An Experimental Study. Journal of Accounting and Investment, 20(2). https:// doi.org/10.18196/jai.2002122

Eliyana, A., Ma'arif, S., \& Muzakki. (2019). Job satisfaction and organizational commitment effect in the transformational leadership towards employee performance. European Research on Management and Business Economics, 25(3), 144-150. https://doi.org/10.1016/j.iedeen.2019.05.001

Febrina, D. (2020). The Influence of Integrity and Commitment Organizational on Employee Performance. 7(1), 799-805

Gao, R. (Chuang R., Murphy, W. H., \& Anderson, R. E. (2020). Transformational leadership effects on salespeople's attitudes, striving, and performance. Journal of Business Research, 110(January), 237-245. https://doi.org/10.1016/j.jbusres.2020.01.023

Hall, J., Johnson, S., Wysocki, A. \& Kepner, K. (2002). Transformational leadership: the transformation of managers and associates. Retrieved August 3, 2006. 1-3.

Henseler, J., Ringle, C. M., \& Sinkovics, R. R. (2009). The use of partial least squares path modeling in international marketing. Advances in International Marketing, 20(January), 277-319. https://doi.org/10.1108/S14747979(2009)0000020014

Indartono. (2018). Perilaku dan Sikap Manajer Produksi Usaha Kecil dan Menengah : Kajian Teori Perilaku. Jurnal Imu Manajemen Vol 15.No.1

Lee, J. (2005). Effects of leadership and leader-member exchange on commitment. Leadership and Organization Development Journal. https://doi.org/10.1108/01437730510633728

Meyer, J. P., \& Allen, N. J. (1984). Testing the "side-bet theory" of organizational commitment: Some methodological considerations. Journal of Applied Psychology, 69(3), 372-378. https://doi.org/10.1037/0021-9010.69.3.372

Mowday, R. T., Porter, L., \& Steers, R. M. (1982). Employe-Organization Linkages: The Psychology of Commitment, Absenteeism \& Turnover. Academic Press.

Mowday, R. T., Steers, R. M., \& Porter, L. W. (1979). The measurement of organizational commitment. Journal of Vocational Behavior. 
https://doi.org/10.1016/0001-8791(79)90072-1

Paracha, B. M. U., Qamar, A., Mirza, A., \& Waqas, H. (2018). " Impact of Leadership Style ( Transformational \& Transactional Leadership ) On Employee Performance \& Mediating Role of Job Satisfaction "Study of Private School ( Educator ) In Pakistan ImpactofLeadershipStyleTransformationalTransactionalLeadershipOnEm. Global Journal of Management and Business Research, 12(4), 55-64.

Qing, M., Asif, M., Hussain, A., \& Jameel, A. (2019). Exploring the impact of ethical leadership on job satisfaction and organizational commitment in public sector organizations: The mediating role of psychological empowerment. Review of Managerial Science, 1-28.

Ramli, A. H. (2019). Organizational Commitment and Employee Performance At Distributor Companies. Business and Entrepreneurial Review, 17(2), 121. https://doi.org/10.25105/ ber.v17i1.5193

Ratnadi, N. M. D., Ariyanto, D., \& Putra, I. N. W. A. (2020). The Vitality of Employee Based Pharmaceutical Brands' Equity in Indonesia: Relationship between Environmental Management Accounting and Organization Performance. Systematic Reviews in Pharmacy, 11(1), 554-563. https://doi.org/10.5530/srp.2020.1.69

Robbins, Stephen P dan Coulter, Mary. 2010. Manajemen. Jilid 1 Edisi 10. Jakarta: Erlangga.

Siswatiningsih, I., Raharjo, K., \& Prasetya, A. (2019). Pengaruh Kepemimpinan Transformasional Dan Transaksional Terhadap Budaya Organisasi, Motivasi Kerja, Komitmen Oganisasional Dan Kinerja Karyawan. Jurnal Bisnis Dan Manajemen, 5(2), 146-157. https://doi.org/10.26905/jbm.v5i2.2388

Sundi, B. K. (2013). Effect of Transformational Leadership and Transactional Leadership on Employee Performance of Konawe Education Department at Southeast Sulawesi Province *). International Journal of Business and Management Invention ISSN (Online, 2(12), 2319-8028.

Tsui, A. S., Pearce, J. L., \& Angela M. Tripoli. (1997). Employee-Organization Relationship: Does Investment In Employees Pay Off? Academy of Management Journal, 40(5), 1089-1122.

Turner, L., Weickgenannt, A., \& Copeland, M. K. (2017). Accounting Information Systems Controls and Processes (Third Edit). Copyright (C) 2017, 2013, 2009 John Wiley \& Sons, Inc.

Urbach, N. Ahlemann, F. (2010). Structural Equation Modeling in Information Systems Research Using Partial Least Squares. International Conference on Information Systems, ICIS 2012, 1(January 2010), 420-432.

Yukl, G. A., \& Becker, W. S. (2006). Effective Empowerment in Organizations. Organization Management Journal, 3(3), 210-231. https://doi.org/10.1057/omj.2006.20

Zefeiti, S. M. B. Al, \& Mohamad, N. A. (2017). The Influence of Organizational Commitment on Omani Public Employees' Work Performance. International Review of Management and Marketing, 7(2), 151-160. http:www.econjournals.com 